\title{
Nucleation and Growth of Alumina Inclusion in Early Stages of Deoxidation: Numerical Modeling
}

\author{
Yan JIN, ${ }^{1)}$ Zhongzhu LIU $^{2)}$ and Ryousuke TAKATA ${ }^{2)}$ \\ 1) Key laboratory for ferrous metallurgy and resources utilization of ministry of education, Wuhan University of Science and \\ Technology, Wuhan 430081 P. R. China. $\quad$ 2) Graduate School of Engineering, Nagoya University, Furo-cho, Chikusa-ku, \\ Nagoya 464-8603 Japan.
}

(Received on August 25, 2009; accepted on December 10, 2009)

\begin{abstract}
In order to gain a better understanding of deoxidation phenomena, there is a need to develop a model that could involve mass transfer, nucleating and growth kinetics of inclusion to simulate unhomogeneous state at the initial stage of Al deoxidation process. Based on the computation of the model for steel droplet with aluminum at center, it is found that the reaction zone between aluminum and oxygen in liquid steel is located in a limited zone at a certain fixed time and it is moved from center to outmost with the time going. For the zone besides the deoxidizer, i.e. aluminum, the supersaturation degree $S_{O}$ is very high at first, and then is decreased quickly, and the main part of oxygen in steel is absorbed by nucleation. In the other side, for the outmost zone, the main part of oxygen in steel is absorbed by growth of inclusion and the growth of inclusion lasts for longer time than that of inner zones.
\end{abstract}

KEY WORDS: alumina inclusion; unhomogeneous state; early stages of deoxidation; model; mass transfer; reaction; nucleation; growth of inclusion.

\section{Introduction}

Deoxidation of steel using aluminum wire injection and further removal of inclusions plays a crucial role in ladle metallurgy. Oxide inclusions, especially hard aluminates, are known to be harmful to the mechanical properties of the steel products. There is ongoing interest in understanding the forming, growth, removing mechanism of oxides inclusions in liquid steel.

It is important to clarify the absorption mechanism of oxygen into $\mathrm{Al}_{2} \mathrm{O}_{3}$ inclusion in early stage of deoxidation, which has a great influence to the morphologies of $\mathrm{Al}_{2} \mathrm{O}_{3}$ inclusion in steel.

E. T. Turkdogan ${ }^{1,2)}$ used the classical nucleation theories to analyze deoxidation of molten steel and homogeneous nucleation of inclusions. Based on his works, ${ }^{1,2)}$ the deoxidation of steel involves the formation of critical nuclei of the deoxidation product, a progress of deoxidation product, and their seperation from the molten steel.

Recently, a lot of researchers, such as W.-C. Doo et al., ${ }^{3)}$ L. Zhang et al., ${ }^{4)}$ T. Nakaoka et al. ${ }^{5)}$ and J. Zhang et al., ${ }^{6}$ ) have tried to develop a general nucleation-growth model, in which inclusions nucleate from homogeneous molten steel and growth due to the diffusion of oxygen and deoxidizer elements, Ostwald ripening and some collision mechanisms. In their models the population balance equations (PBE) of inclusions are solved, and the particle size distribution (PSD) of inclusions in molten steel at early stage are investigated.

Meanwhile, for the unhomogeneous state at the initial stage of $\mathrm{Al}$ deoxidation process, K. Beskow et l. $^{7)}$ develop comprehensive model involving fluid flow, deoxidation kinetics, and removal of deoxidation products to simulate the concentration profiles of oxygen and aluminum during deoxidation by aluminum wire injection. For the deoxidation reaction, the source terms of the concentration controlling equations have been computed assuming that local thermodynamic equilibrium is achieved.

In order to gain a better understanding of deoxidation phenomena, there is need to develop a model that could involve mass transfer, nucleating and growth kinetics of inclusion to simulate unhomogeneous state at the initial stage of $\mathrm{Al}$ deoxidation process.

In the present work, observation of $\mathrm{Al}$ oxide inclusion in the un-uniform concentration fields at the initial stage of $\mathrm{Al}$ deoxidation process in steel droplet has been conducted. A one-dimension spherical coordinate mass transfer and reaction model has been developed to simulate of the concentration profiles of oxygen, aluminum and alumina in steel droplet, and the calculation results are used to analyse the morphology of the $\mathrm{Al}_{2} \mathrm{O}_{3}$ inclusions in steel droplet.

\section{Model Formulation}

The steel droplet with certain initial oxygen and aluminum in the center represents a unsteady state diffusion pattern in hemispherical and semisolidified steel phase, as shown in Fig. 1. Based on one dimension spherical coordinate mass transfer and reaction model the concentration field of the oxygen, aluminum and alumina in the liquid 


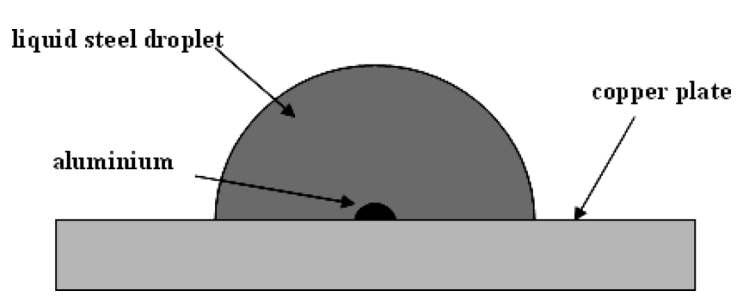

Fig. 1. The sketch of aluminium in the steel droplet.

steel droplet is calculated. The nucleation and growth of alumina inclusion has been represented through source terms in the conservation equations.

\subsection{Assumptions}

The principal assumptions of the model:

(1) The shape of the liquid steel droplet is hemispheroid, and the surface and bottom of the droplet are boundary for the calculation.

(2) For convective mass transferring caused by the convecting flow in the liquid droplet, an effective diffusion coefficient is introduced to stand for overall mass transporting.

(3) For $\mathrm{Al}_{2} \mathrm{O}_{3}$ inclusion, the concentration field of it is calculated with consideration of reaction only. After the supersaturation degree $S_{\mathrm{O}}\left(S_{\mathrm{O}}=K_{\mathrm{AlO}} / K_{\text {eq.(O) }}, K_{\mathrm{AlO}}=[\% \mathrm{Al}]^{2 / 3}\right.$ [\%O], $K_{\text {eq.(O) }}$ is $K_{\mathrm{AlO}}$ under the equilibrium state) is higher than the critical degree, $\mathrm{Al}_{2} \mathrm{O}_{3}$ inclusions are nucleated. After the nucleation period, the free oxygen atom in the liquid steel is transferred to the surface of aluminium and then reacted with the aluminium and the reacted alumina is aggregated onto the surface of $\mathrm{Al}_{2} \mathrm{O}_{3}$ inclusion and, the control step is the convective mass transfer of reactants.

(4) Aluminium is in the center of steel droplet, and is also hemispheric. In the experiment it is observed that after the aluminium wire is inserted into liquid steel, the Al-Fe alloy with $\mathrm{Al}$ content of $30 \%$ is soon formed outside of the aluminium wire, but the boundary of liquid steel and $\mathrm{Fe}-\mathrm{Al}$ alloy is clear in image, the Al content at the boundary is almost fixed, and the shape of the residual Al wire with outside Al-Fe alloy is close to sphere. For simplifying the model, the shape aluminum is assumed as sphere. At the interface of aluminium and liquid steel, $[\% \mathrm{Al}]$ is taken a fix value according to experiment results.

\subsection{Transport Equations}

The concentration profiles of $\mathrm{O}$ and $\mathrm{Al}$ are computed in transient mode. These equations have the following forms:

For $\mathrm{Al}$ :

$$
\frac{\partial C_{\mathrm{Al}}}{\partial t}=\frac{1}{r^{2}} \frac{\partial}{\partial r}\left(r^{2} D_{\mathrm{eff}(\mathrm{Al})} \frac{\partial}{\partial r} C_{\mathrm{Al}}\right)+S c_{\mathrm{Al}}
$$

For O:

$$
\frac{\partial C_{\mathrm{O}}}{\partial t}=\frac{1}{r^{2}} \frac{\partial}{\partial r}\left(r^{2} D_{\text {eff(O) }} \frac{\partial}{\partial r} C_{\mathrm{O}}\right)+S c_{\mathrm{O}}
$$

For $\mathrm{Al}_{2} \mathrm{O}_{3}$

$$
\frac{\partial C_{\mathrm{Al}_{2} \mathrm{O}_{3}}}{\partial t}=S c_{\mathrm{Al}_{2} \mathrm{O}_{3}}
$$

where,

$D_{\text {eff }}=$ equivalent diffusion coeffient, $\mathrm{m}^{2} / \mathrm{s}$

$$
\begin{array}{ll}
S c & =\text { the source term } \\
r & =\text { radium }, \mathrm{m} \\
t & =\text { time, } \mathrm{s}
\end{array}
$$

\subsection{Equivalent Diffusion Coeffient}

$D_{\text {eff }}$ can be calculated with the following relationship:

$$
D_{\mathrm{eff}(i)}=m_{1} \cdot D_{(i)} \quad i=\mathrm{Al}, \mathrm{O} .
$$

where, $m_{1}=$ equivalent coefficient for convective mass transfer.

According definition of sherwood number, $m_{1}=s h+1$, and sherwood number can be calculated with following equation:

$$
S h=0.664 \operatorname{Re}_{1 / 2} S c_{1 / 3}
$$

For the liquid steel, $S c$ number is close to 1000 . As the liquid droplet is soon frozen on the water cooling copper plate within $5 \mathrm{~s}$ based on the heat transfer computation, Re number of the semi-solidied liquid steel is very low, in this study its value is taken to one. So the value of $m_{1}$ is close to 8 .

\subsection{Source Term}

For the source term, the chemical reaction is considered:

$$
\begin{gathered}
2 \mathrm{Al}+3 \mathrm{O}=\mathrm{Al}_{2} \mathrm{O}_{3 \text { (solid) }} \cdots \cdots \\
\Delta G^{\circ}=-1209490+391.4 T .
\end{gathered}
$$

For the source terms in above transport equations, they have the following relation with each other:

$$
S c_{(\mathrm{O})}=S c_{(\mathrm{Al})} \cdot \frac{3 \times 16}{2 \times 27}=S c_{\left(\mathrm{Al}_{2} \mathrm{O}_{3}\right)} \cdot \frac{3 \times 16}{2 \times 27+3 \times 16}
$$

The reaction will take place in the area where the supersaturation degreee should be above the critical level (=14.7, measured by H. Suito, ${ }^{9}$ ) and the theoretic value is equal to 529), only in $6.58 \times 10^{-6} \mathrm{~s}^{4)}$ the nucleation period is ended, and after nucleation stage, no more nuclei of $\mathrm{Al}_{2} \mathrm{O}_{3}$ are formed. For the addition of $\mathrm{Al}$, the following equation defines how fast the $\mathrm{Al}_{2} \mathrm{O}_{3}$ inclusion appear and disperse in the liquid steel after the supersaturation degree above the criteria level:

$$
\begin{aligned}
& \text { For } S_{\mathrm{O}}>14.7, t-t_{\mathrm{c}}<6.58 \times 10^{-6} \mathrm{~s} \\
& \qquad Q_{\mathrm{O}}=\left(C_{\mathrm{O}}-C_{\mathrm{Oe}}\right)\left\{1-\exp \left[-2.45 \times 10^{5} \times\left(t-t_{\mathrm{c}}\right)\right]\right\} \ldots
\end{aligned}
$$

where

$Q_{\mathrm{O}} \quad=$ the amount of oxygen content removed from liquid steel by nucleation of aluminia inclusion, $\mathrm{mol} / \mathrm{m}^{3}$

$C_{\mathrm{Oe}}=$ equilibrium content of oxygen in liquid steel, $\mathrm{mol} / \mathrm{m}^{3}$

$t_{\mathrm{c}} \quad=$ time when $S_{\mathrm{O}}$ starts to be above the criteria level at that position, $\mathrm{s}$

$$
S c_{\mathrm{O}}=\frac{\partial Q_{\mathrm{O}}}{\partial t}
$$

After the peroid of nucleation, the reactants are absorbed to the inclusion to form $\mathrm{Al}_{2} \mathrm{O}_{3}$ through convective mass transfer. 


$$
\begin{aligned}
& \text { For } S_{\mathrm{O}}>1, t-t_{\mathrm{c}}>6.58 \times 10^{-6} \mathrm{~s} \\
& \qquad S c_{\mathrm{O}}=-4 \pi \bar{r}_{\mathrm{p}}^{2} N_{\mathrm{p}} \cdot\left(\frac{D_{(\mathrm{O})}}{\bar{r}_{\mathrm{p}}}\right) \cdot\left(C_{\mathrm{O}}-C_{\mathrm{Oe}}\right)
\end{aligned}
$$

$\bar{r}_{\mathrm{p}}$ is mean radium of the inclusion, $\bar{r}_{\mathrm{p}}$ is taken as $0.4 \mu \mathrm{m}$ in the early stage of deoxidation. ${ }^{9)} N_{\mathrm{p}}$ is the number of inclusion per unit volume, in the early stage of deoxidation $N_{\mathrm{p}}$ is equal to $5 \times 10^{14} \mathrm{~m}^{-3}$. .)

The calculation of the aboving equations needs the equilibrium value of $[\% \mathrm{O}]$ and $[\% \mathrm{Al}]$. The equilibrium constant $\left(k_{\text {eq }}\right)$ for reaction $(6)$ can be described as:

$$
k_{\mathrm{eq}}=\frac{1}{f_{\mathrm{N}}^{2}([\% \mathrm{Al}]-\Delta[\% \mathrm{Al}])^{2} f_{\mathrm{O}}^{3}([\% \mathrm{O}]-0.889 \cdot \Delta[\% \mathrm{Al}])^{3}}
$$

where $f_{\mathrm{Al}}$ and $f_{\mathrm{O}}$ are the activity coefficients of $\mathrm{Al}$ and $\mathrm{O}$, respectively. In this study $f_{\mathrm{Al}}^{2} \cdot f_{\mathrm{O}}^{3}$ is taken as 1 .

\subsection{Condition of Definite Solution}

(1) Initial condition

$$
\left\{\begin{array}{l}
C_{\mathrm{O}(r, 0)}=C_{\mathrm{in}} \\
C_{\mathrm{Al}(r, 0)}=0 \\
C_{\mathrm{Al}_{2} \mathrm{O}_{3}(r, 0)}=0
\end{array}\right.
$$

where $C_{\mathrm{in}}=$ the oxygen concentration at initial time, $\mathrm{mol} / \mathrm{m}^{3}$.

(2) Boundary condition:

At the interface between aluminium and steel, the aluminium content equal to a fix value, based on the experimental data.

$$
r=r_{\mathrm{Al}} ; C_{\mathrm{Al}(r \mathrm{Al}, t)}=C_{\mathrm{b}}
$$

where

$$
\begin{aligned}
r_{\mathrm{Al}}= & \text { the radium of aluminium in the center of } \\
& \text { droplet, } \mathrm{m} \\
C_{\mathrm{b}}= & \text { the fixed aluminium concentration at the inter- } \\
& \text { face, } \mathrm{mol} / \mathrm{m}^{3}
\end{aligned}
$$

\subsection{Numerical Procedure}

The transport equations can be solved using a fixed grid numerical solution procedure. For the results presented in this article, an imlicit finite difference scheme has been used to discrete the conservation equations. The implicit equations are handled using inverse matrix algorithm.

\section{Experimental Procedure}

The steel sample used in this experiment is prepared in an induction heating furnace with electrolytic iron.

Figure 2 shows the experimental setup. The tungsten coil around the silica nozzle is used to heat up the steel sample in the nozzle up to $1873 \mathrm{~K}$. The interior of the total setup is purged with argon to keep at an inert atmosphere. After the steel sample is melted, the pressure in the silica nozzle is suddenly surged by the hypodermic syringe, and the molten steel is dropped onto a water-cooled copper plate, on which a small aluminum wire is standing to dissolve into the steel.

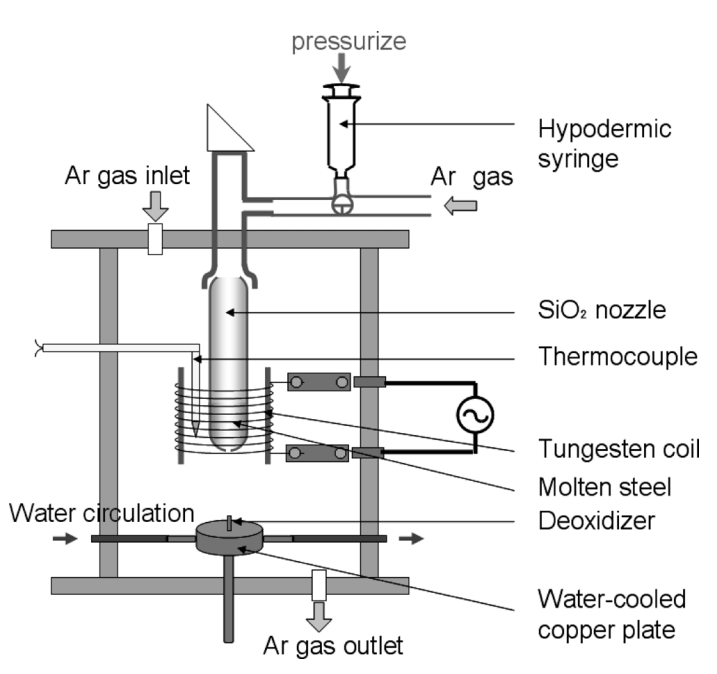

Fig. 2. Experimental setup.

Table 1. Experimental conditions.

\begin{tabular}{|c|c|}
\hline Steel mass & $2.5 \mathrm{~g}$ \\
\hline Nozzle & Silica $(9.5 \mathrm{~mm}$ in diameter $)$ \\
\hline Temperature & $1873 \mathrm{~K}$ \\
\hline Deoxidizer & $\begin{array}{c}\text { Al wire }(1.0 \mathrm{~mm} \text { in diameter } \times \\
3 \mathrm{~mm} \text { in height })\end{array}$ \\
\hline Initial oxygen content & $80,200,600 \mathrm{ppm}$ \\
\hline Cooling method & Water cooled Cu plate or \\
& dense $\mathrm{MgO}$ plate \\
\hline
\end{tabular}

In order to regulate cooling intensity, the copper plate is covered with $\mathrm{MgO}$ plate in some heats of the experiment.

The experimental conditions are listed in Table 1. The inclusions in the samples are observed with scanning electron microscopy (SEM).

\section{Results and Discussions}

\subsection{Inclusion in Droplet}

For the dropping experiment, the thin aluminum wire is only partly soluted into the steel, and there is aluminum in liquid state in the center of droplet. The line EDS analysis results arround the interface between the remaining aluminum and steel is shown in Fig. 3. From the figure, it is found that the $[\% \mathrm{Al}]$ is around $5-7$ at the liquid steel side of the interface.

With digital simulation the solidification process of the steel droplet, which is verified by the location of shrinkage cavity observed by laser microscope. It is concluded that the steel droplet is solidfied quickly in $4.3 \mathrm{~s}$ on water cooling copper plate, and in $3 \mathrm{~s}$ there is half of the droplet is frozen to solid. It takes $9.4 \mathrm{~s}$ for the complete solidying of steel droplet on $\mathrm{MgO}$ plate that placed on copper plate, and in $8 \mathrm{~s}$ there is half of the droplet is in mushy zone. According to the result of the simulation, quenching solidifying only influences the zone with the distance from the bottom plate less than $1 \mathrm{~mm}$, and for the nucleation and growth time of inclusion is far less than $1 \mathrm{~s}$, the influence of solidication of droplet is small to that of inclusion.

For the observation of inlusion, the droplet is classified 

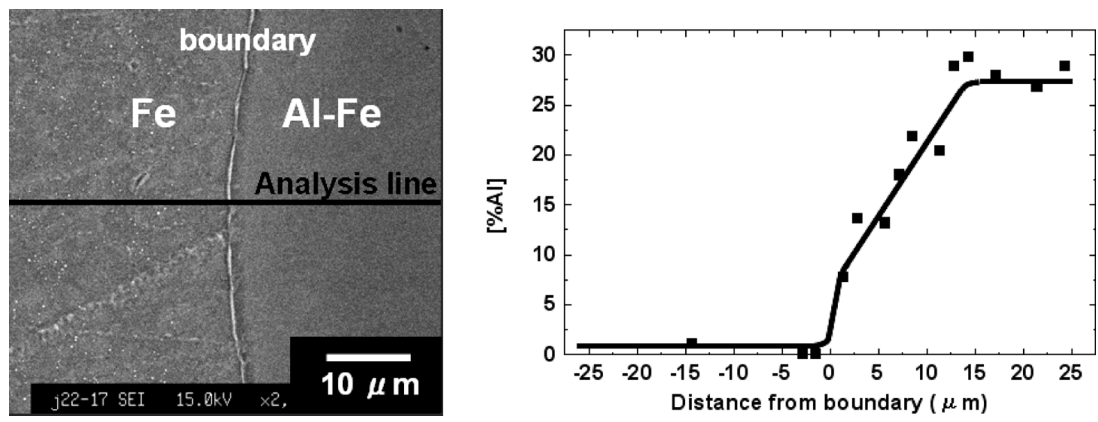

Fig. 3. EDS analysis of $\mathrm{Al}$ concentration around $\mathrm{Al} / \mathrm{Fe}$ interface.

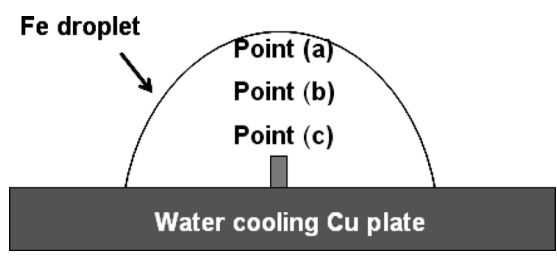

Fig. 4. Schematically location of the observation: point (a), (b) and (c).

into 3 locations, i.e. location (a), (b), and (c), Fig. 4. The morphologies of inclusions at each location are listed in Table 2, and the inclusions are classified into 4 types of morphologies, that is, sphere, aggregation, early stage of inclusion growth, and dendrite, as shown in Fig. 5. For the sphere type inclusion, the shape of this type is sphere and the size of this type is often less than $1 \mu \mathrm{m}$; for the aggregation type inclusion, the inclusions are consisted of several sphere alumina with the size of $0.1-1 \mu \mathrm{m}$, and the tiny alumina are aggregated in the zone with the size more than $1 \mu \mathrm{m}$; for the early stage type inclusion, this type of inclusion is in the early stage of growth, the primary dendrite of the inclusion is in the early stage of growth; for dendrite type inclusion, the dendrite of inclusions is fully developed, and the inclusion can be grown into equiaxial alumina or alumina with one-direction dendrite. Based on the observation, from location (c) to (b), the number of early stage inclusion is decreased, and from location (c) to (a), the number of sphere inclusion is increased. At location (b) and (a), there are dendrite inclusions appearing.

The number distribution of inclusions of each type in one viewing field of SEM at all the above three location is also plotted in the Fig. 5(f).

\subsection{Concentration Profile}

To model the concentration profile of the droplet with certain initial oxygen and aluminum in the center, some important parameters are necessary and listed in Table $\mathbf{3}$ and Table 4.

Figure 6 are the concentration field and supersaturation profile in the liquid steel droplet on the water cooling copper plate with aluminum in the center and initial oxygen content of $200 \mathrm{ppm}$. In the Fig. 6(e), it is found that as the time moves from 1 to $2 \mathrm{~s}$, the $\mathrm{Al}-\mathrm{O}$ reaction zone moves from less than 1 to $1.5 \mathrm{~mm}$ off the aluminium wire, and the peak value of supersaturation degree $\left(S_{\mathrm{O}}\right)$ is sharply decreased from 25 to 12.5. In the same area, the observed sum number of alumina inclusion is decreased from 160 to 60 in
Table 2. Overview of the inclusion shape.

\begin{tabular}{|c|c|c|c|}
\hline & Exp.(90 ppm O) & Exp. (210 ppm O) & Exp. (585 ppm O) \\
\hline \multirow{3}{*}{ Point (a) } & $\mathrm{sp}$ & $\mathrm{sp}$ & $\mathrm{sp}$ \\
& $\mathrm{ag}$ & $\mathrm{ag}$ & $\mathrm{ag}$ \\
& $\mathrm{esig}$ & $\mathrm{de}$ & $\mathrm{de}$ \\
\hline \multirow{3}{*}{ Point (b) } & $\mathrm{sp}$ & $\mathrm{sp}$ & $\mathrm{sp}$ \\
& $\mathrm{esig}$ & $\mathrm{ag}$ & $\mathrm{de}$ \\
\hline \multirow{3}{*}{ Point (c) } & $\mathrm{de}$ & $\mathrm{esig}$ & $\mathrm{sp}$ \\
& $\mathrm{sp}$ & $\mathrm{sp}$ & $\mathrm{ag}$ \\
& $\mathrm{esig}$ & $\mathrm{ag}$ & $\mathrm{esig}$ \\
\hline
\end{tabular}

sp : sphere

ag : aggregation

esig : early stage of inclusion growth

de : dendrite

one field of microsope vision. As the time moves from 2 to $3 \mathrm{~s}$, the Al-O reaction zone moves from less than 1.5 to $2.3 \mathrm{~mm}$ off the aluminium wire, and the peak value of $S_{\mathrm{O}}$ keeps at 12.5, and the sum number of alumina inclusion in one vision field also keeps at 55-60. As the supersaturation degree determines the nucleation rate of inclusions, the area with higher $S_{\mathrm{O}}$ value may have more number of inclusions. So the calculation results of the model agrees with phenomenon observed in the actual sample.

From above Fig. 6, it is shown that high aluminium zone is gradually diffused from the center of the droplet to the outsider, while high oxygen zone in the droplet is withdrawed with almost constant speed in the same direction in the same time. At the position where is overlapped by high aluminium and oxygen zone, there is high supersaturation degree, and the high supersaturation zone is moving from center to outsider with time going, while the peak supersaturation degree is decreased with time going. This means that the reaction zone between aluminum and oxygen in liquid steel is located in a limited zone at a certain fixed time and it is moved from center to outmost with the time going.

For the $\mathrm{Al}_{2} \mathrm{O}_{3}$ distribution in the steel droplet, there ia a homogeneously distribution zone near the center aluminium zone, then the $\mathrm{Al}_{2} \mathrm{O}_{3}$ content is increased sharply and then there is a peak appearing, and outside of the peak zone the $\mathrm{Al}_{2} \mathrm{O}_{3}$ content is increased slowly with the increasing of the distance from the center, at the edge of the $\mathrm{Al}_{2} \mathrm{O}_{3}$ area its content is decreased sharply. 


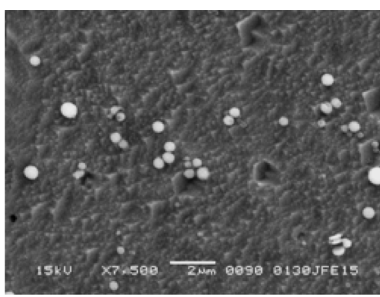

(a) Sphere

(200 ppmO, point (a))

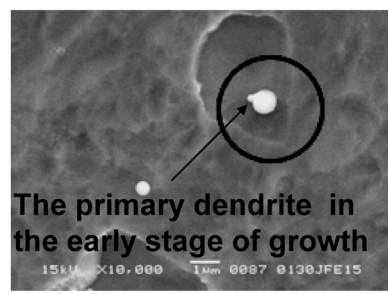

(b) Early stage of inclusion growth (200 ppm O, point (b))

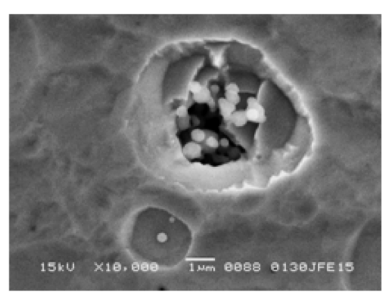

(c) Aggregation

(200 ppm O, point (b))

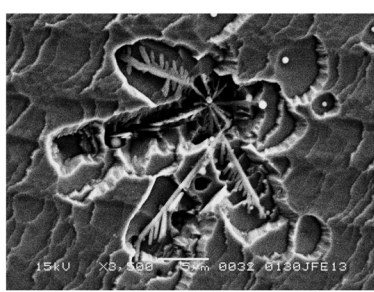

(d) Dendrite

(600 ppm O, point (a))

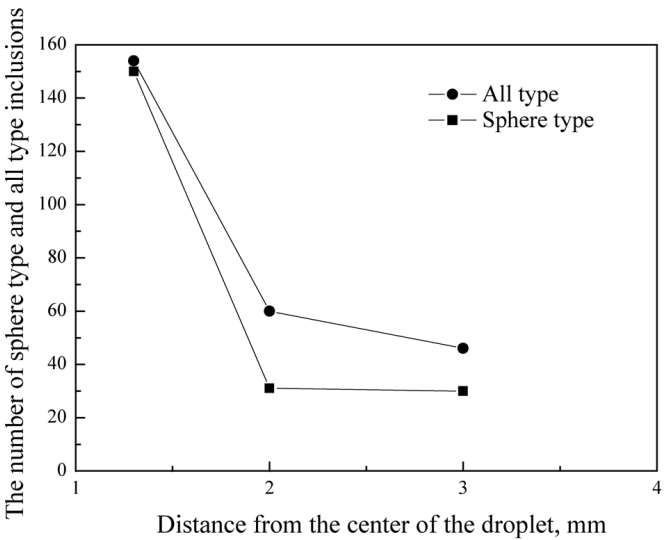

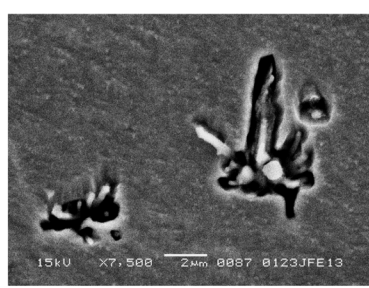

(e) Dendrite

(600 ppm O, point (b))

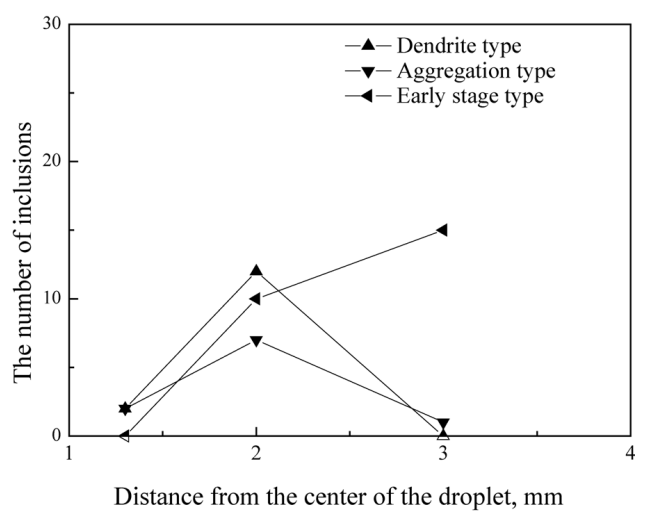

(f) The number of inclusions of each type in one viewing field of SEM

Fig. 5. SEM images of typical inclusions.

Table 3. Physical property parameters.

\begin{tabular}{|c|c|c|c|}
\hline Coefficients & $D_{\mathrm{Al}}, \mathrm{m}^{2} / \mathrm{s}^{7)}$ & $D_{\mathrm{O}}, \mathrm{m}^{2} / \mathrm{s}^{7)}$ & $m_{1}$ \\
\hline Value & $1.12 \times 10^{-8}$ & $3.34 \times 10^{-7} \times \exp (-50200 / \mathrm{RT})$ & 8 \\
\hline
\end{tabular}

Table 4. Simulation parameters for the model.

\begin{tabular}{|c|c|c|c|c|c|c|}
\hline Parameters & $r_{\mathrm{d}}, \mathrm{m}$ & $r_{\mathrm{Al}}, \mathrm{m}$ & {$[\% \mathrm{Al}]_{\mathrm{b}}, \%$} & {$[\% \mathrm{O}]_{\mathrm{in}}, \%$} & $t_{\max }, \mathrm{s}$ & $T_{\text {droplet }}, \mathrm{K}$ \\
\hline Value & 0.0072 & 0.001 & 5 & $0.02,0.04,0.06$ & 5 & 1763 \\
\hline
\end{tabular}

\subsection{Nucleation and Growth of Inclusion at Different Location in Liquid Steel}

Based on the distribution of $\mathrm{Al}_{2} \mathrm{O}_{3}$, the droplet can be divided to four regions, as shown in Fig. 7: the zone besides aluminum (I zone), the peak zone (II zone), the middle zone (III zone) and the outmost zone (IV zone). The trend curve of pricipating rate of $\mathrm{Al}_{2} \mathrm{O}_{3}$ at the typical point (i.e. point $\mathrm{A}, \mathrm{B}, \mathrm{C}, \mathrm{D}$ and $\mathrm{E}$ ) in the each regions have different pattern, as shown in Fig. 8. In Figs. 7 and 8, $\% \mathrm{Al}_{2} \mathrm{O}_{3}$ stands for the weight percent ratio of precipitated $\mathrm{Al}_{2} \mathrm{O}_{3}$ versus liquid steel.

\subsubsection{The Zone Besides Aluminum (I Zone)}

The I zone is just beside the center, where there is alu- minium, and in this region the aluminia content is not very high but is even distributed, as shown in I zone of Fig. 7. The precipitating rate of $\mathrm{Al}_{2} \mathrm{O}_{3}$ in this region is very high at the start time, but is quickly decreased to zero, as shown in the curve of A point in Fig. 8. For A point in I zone, the ratio of oxygen in steel absorbed by nucleation can reach $74 \%$ based on the computation of the model, that means the main part of $\mathrm{Al}_{2} \mathrm{O}_{3}$ precipitated by nucleation. The curve of the supersaturation $\left(S_{\mathrm{O}}\right),[\% \mathrm{Al}]$ and $[\% \mathrm{O}]$ versus time at point $\mathrm{A}$ (the position of point $\mathrm{A}$ is shown in Fig. 7) in I region is shown in Fig. 9. It is found that the [\%Al] is increased to $1 \%$ in less than $0.5 \mathrm{~s}$, and in the same time the $[\% \mathrm{O}]$ is decreased to less than $10^{-4}$. When $[\% \mathrm{O}]$ is less than $10^{-4}$, the rate of deoxidation reaction is very low. From the Fig. 9, the supersaturation degree $S_{\mathrm{O}}$ is very high at first, and then is decreased from nearly 1000 to less than 100 in less than $0.3 \mathrm{~s}$.

As the above mention, the nucleation rate of inclusion in this zone is very high, the growth of inclusion is limited in a very short time. The characteristics of inclusion in this region is that the number is high and the mean size is low, main part of inclusion is the sphere type inclusion with tiny size, as shown in Fig. 5(a). 
ISIJ International, Vol. 50 (2010), No. 3

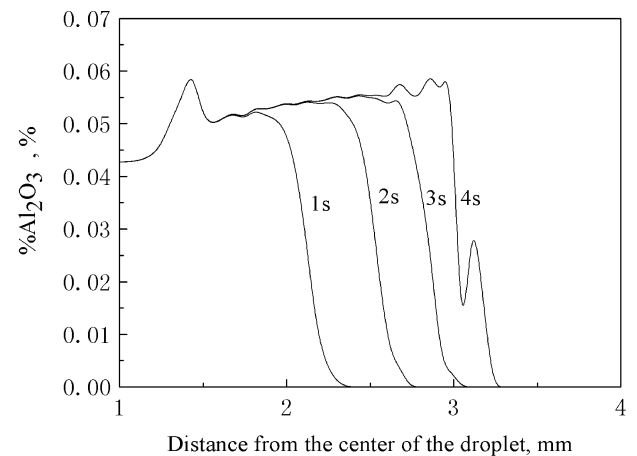

(a)

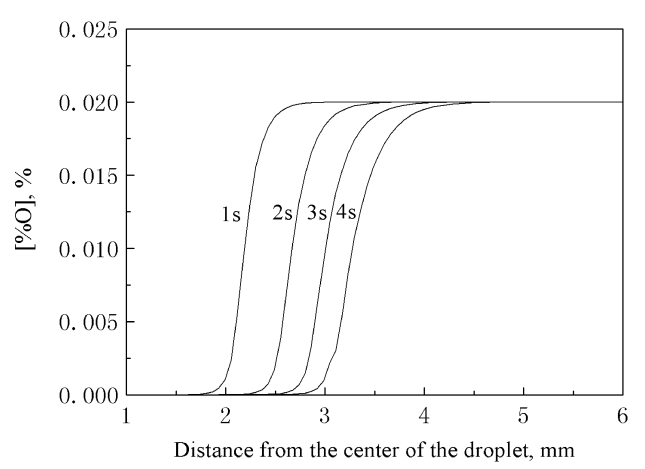

(c)

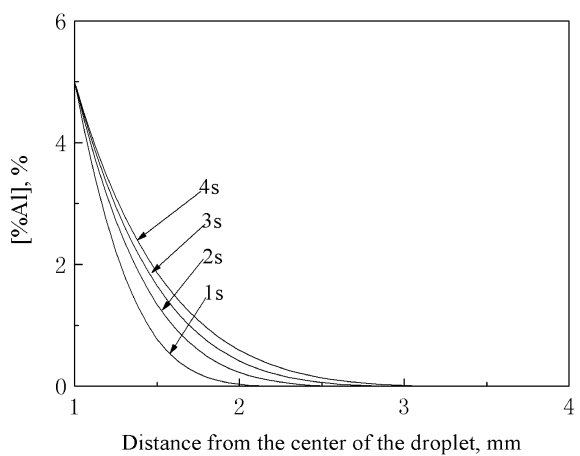

(b)

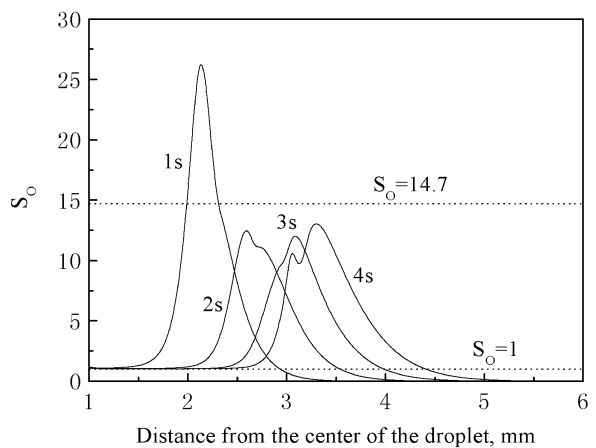

(d)

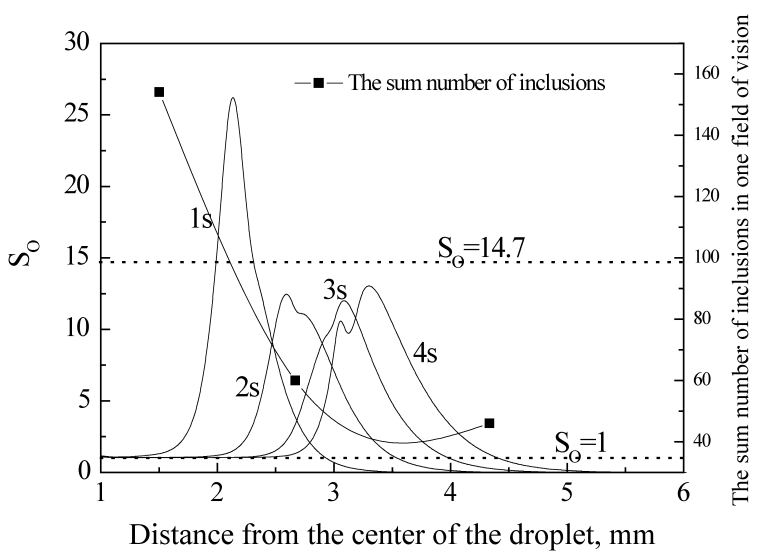

(e) The comparison between $\mathrm{S}_{\mathrm{O}}$ and the sum number of inclusions in one 1000 times field of vision

Fig. 6. Simulating the droplet contain $200 \mathrm{ppm}$ oxygen on copper plate.

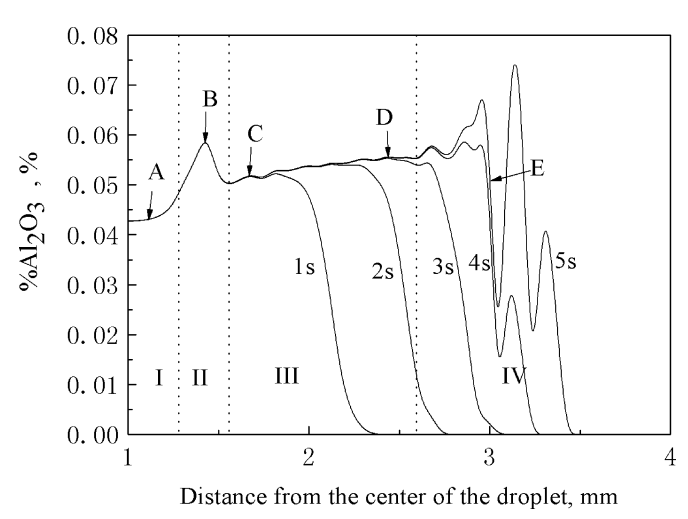

Fig. 7. The four regions inside the liquid steel droplet.

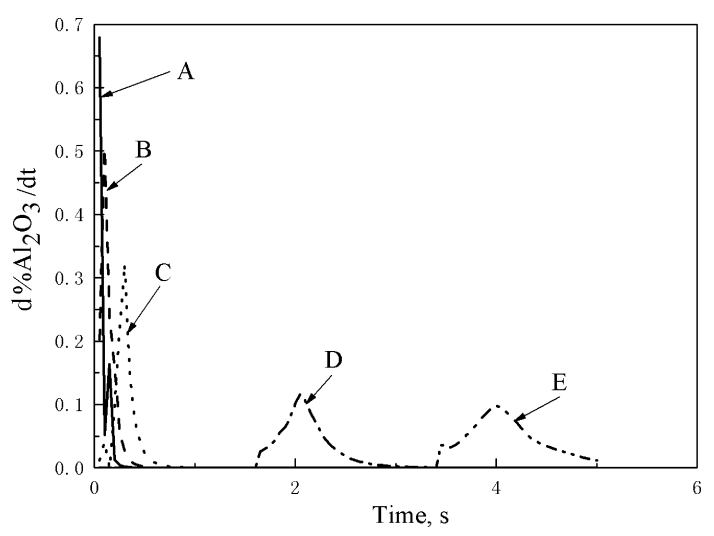

Fig. 8. The trend of pricipate rate of $\mathrm{Al}_{2} \mathrm{O}_{3}$ at the typical point. 


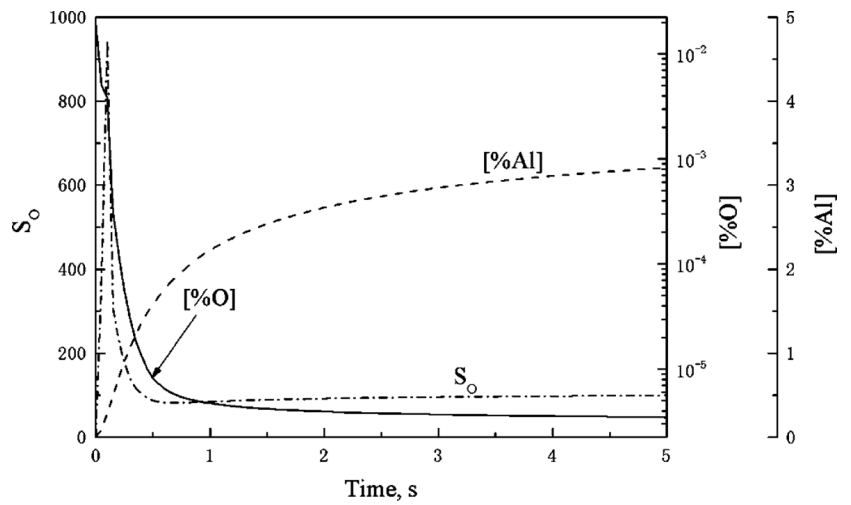

Fig. 9. The curve of $\mathrm{S}_{\mathrm{O}}$, $[\% \mathrm{Al}]$ and $[\% \mathrm{O}]$ at point $\mathrm{A}$ of Fig. 7.

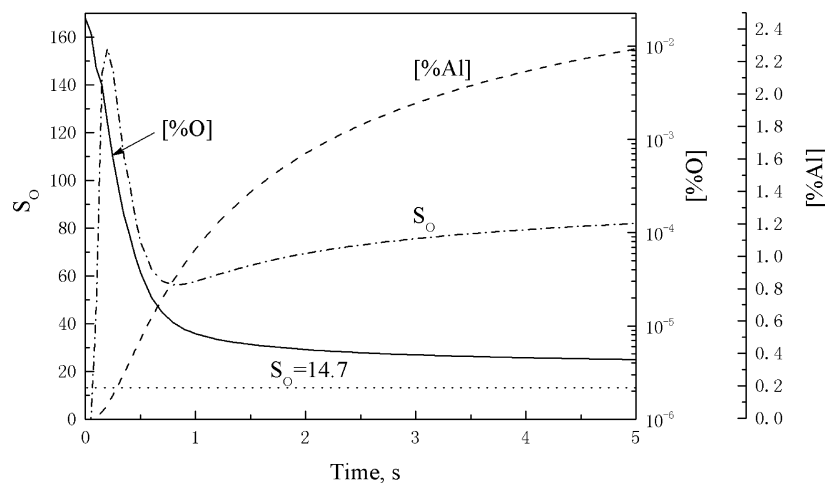

Fig. 10. The curve of $\mathrm{S}_{\mathrm{O}}$, $[\% \mathrm{Al}]$ and $[\% \mathrm{O}]$ at point $\mathrm{B}$ of Fig. 7 .
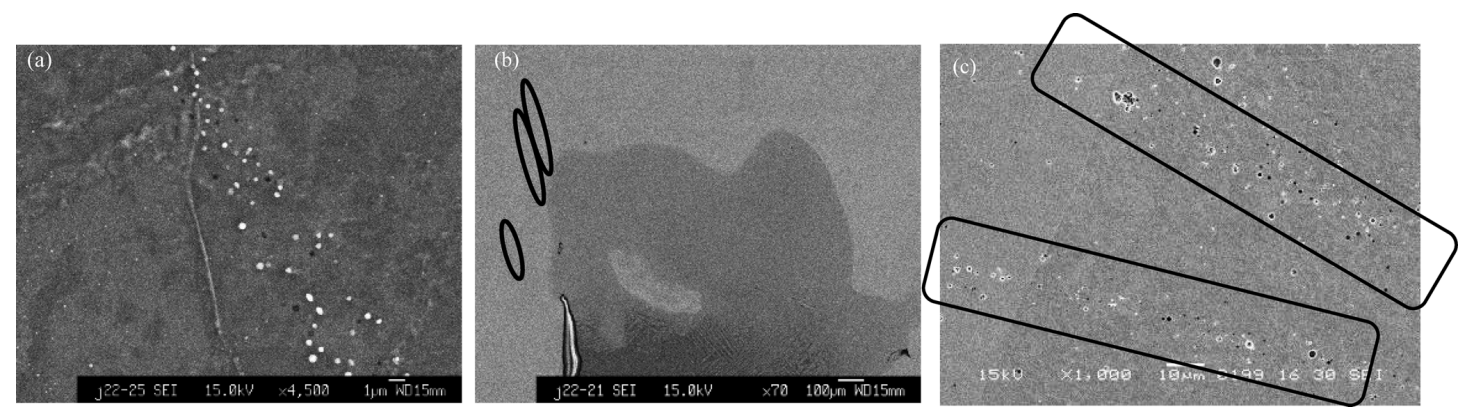

Fig. 11. Layer-like alumina inclusion around un-dissolved Al.

\subsubsection{The Peak Zone (II Zone)}

The II zone has the peak of the $\mathrm{Al}_{2} \mathrm{O}_{3}$ content (point $\mathrm{B}$ in Fig. 7). The reason is that it takes a little time for the aluminum is diffused to this location, in the same time $[\% \mathrm{O}]$ is not decreased, the supersaturation is also very high at first and the high value of $S_{\mathrm{O}}$ lasts for the time $(>0.8 \mathrm{~s})$ far more than that of I zone $(<0.3 \mathrm{~s})$, Fig. 10. All this causes the precipitate rate of $\mathrm{Al}_{2} \mathrm{O}_{3}$ is very high and the high value lasts for a while, as shown in Fig. 8 (point $\mathrm{B}$ ). So the $\mathrm{Al}_{2} \mathrm{O}_{3}$ content forms a peak in this region.

In the observation of inclusion morphologies for the droplet in the dropping experiment, it is often found straight-line band of inclusion just beside the aluminium zone, Fig. 11. As the $[\% \mathrm{O}]$ is decreased to very low level at this region long before solidification, and can not cause $\mathrm{Al}_{2} \mathrm{O}_{3}$ precipitation during solidification, this part of inclusion is considered to be formed in liquid steel. This straight-line bands of inclusions, which are often located in the I and II zone based on the SEM images, may be the sign of the reaction zone with high nucleation in I and II zone, as the peak content of $\mathrm{Al}_{2} \mathrm{O}_{3}$ makes distribution of inclusion in this zone more visible.

\subsubsection{The Middle Zone (III Zone)}

The III zone is the one in which $\mathrm{Al}_{2} \mathrm{O}_{3}$ level is not very high and is even distributed. From the Fig. 7, the precipitate rate of $\mathrm{Al}_{2} \mathrm{O}_{3}$ in this region (point $\mathrm{C}$ and $\mathrm{D}$ ) is not as high as region $\mathrm{I}$ and $\mathrm{II}$, but lasting time is obviously longer than that in the former two regions. The supersaturation $S_{\mathrm{O}}$ is not so high, and [\%Al] is not very high, Figs. 12 and 13. In this region, after the nucleation of inclusion, there is enough $[\% \mathrm{O}]$ for continuing growth of the inclusion, and the growth of inclusion plays an important role in this region.

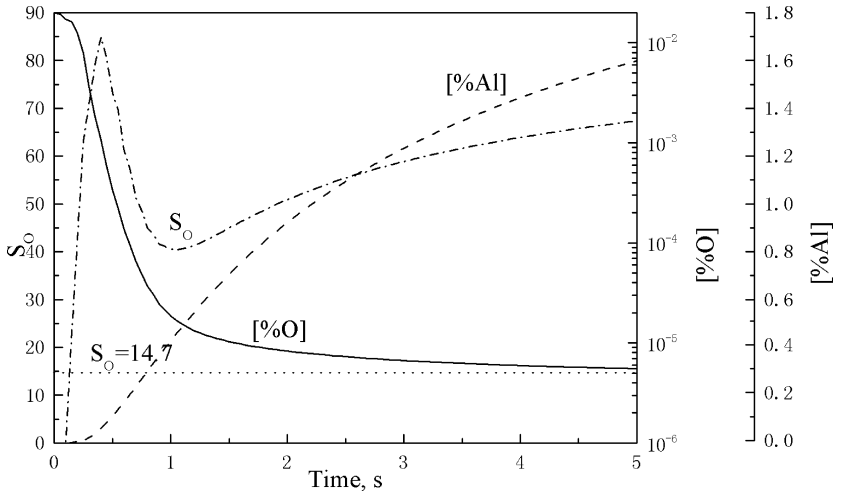

Fig. 12. The trend of $\mathrm{S}_{\mathrm{O}},[\% \mathrm{Al}]$ and $[\% \mathrm{O}]$ at point $\mathrm{C}$ of Fig. 7.

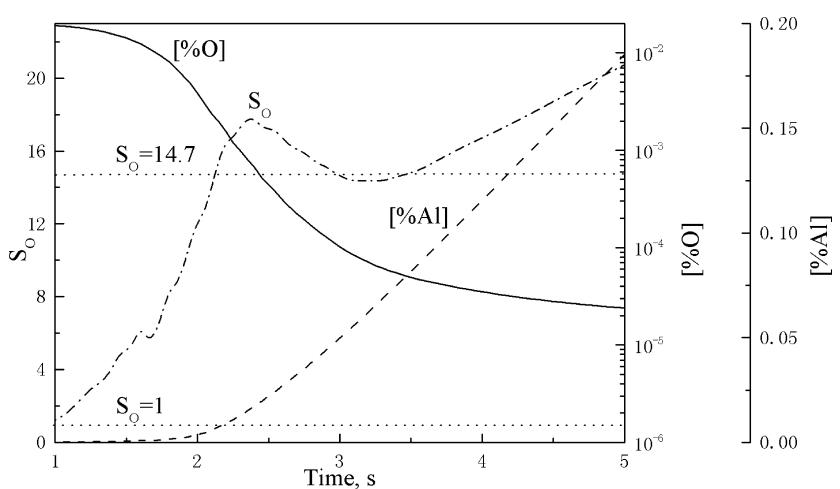

Fig. 13. The trend of $\mathrm{S}_{\mathrm{O}},[\% \mathrm{Al}]$ and $[\% \mathrm{O}]$ at point $\mathrm{D}$ of Fig. 7.

Based on the calculation of the model, the ratio of oxygen absorbed by growth of inclusion is increased to $88 \%$ at point C. And from Fig. 6, it is found that the isoconcentration line of $[\% \mathrm{Al}]$ in this region is very dense, so the inclusion in this region may grow in radial direction, and be- 
come a orientated growth dendrite type inclusion just as observation of inclusion morphologies in actual droplet, Fig. 5(e).

\subsubsection{The Outmost Zone (IV Zone)}

The IV zone is the area in which inclusion is not distributed evenly. From the Fig. 7, the precipitate rate of $\mathrm{Al}_{2} \mathrm{O}_{3}$ in this region (point $\mathrm{E}$ ) is not as high as the inner regions, but the duration time of pricipitation is the longest. The supersaturation So is the lowest, $[\% \mathrm{Al}]$ is not high, and $[\% \mathrm{O}]$ is high even at the solidification end of the droplet, Fig. 14. According to the model, the ratio of oxygen absorbed by growth of inclusion is increased to $98 \%$ at point E. $S_{\mathrm{O}}$ in this region, after the nucleation of inclusion, there is less nuclei of the inclusion than the inner regions, the growth of inclusion plays an main role in this region, and as low number of nuclei the growth of the inclusion is quit free. And from Fig. 6 , it is found that $[\% \mathrm{Al}]$ in this region is the very low compared with the inner side, so the reaction can not take place in each location, and the inclusion in this region may growth into equiaxed dendritic alumina, Fig. 5(d).

\subsection{The Influence of Solidification}

As the model is simulating the steel droplet which quickly solidified in copper plates in $4.3 \mathrm{~s}$. The influence of solidification should be considered, as the oxygen can be segregated before the solidification front.

Based on the model proposed by H. D. Brody and M. C. Fleming, ${ }^{10)}$ the segregation ratio of Oxygen $\left(R^{*}=C^{*}{ }_{\mathrm{L}} / C_{0}\right.$, where $C^{*}{ }_{\mathrm{L}}$ is the equilibrium content of $\mathrm{O}$ in the liquid steel, and $C_{0}$ is the average content of $\mathrm{O}$ in the total steel include liquid and solid phases) is increased from 1 to 6 , with

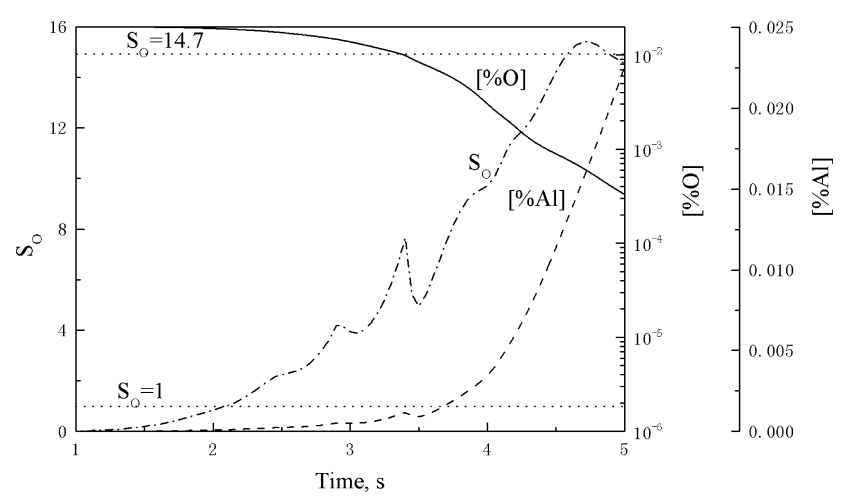

Fig. 14. The trend of $\mathrm{S}_{\mathrm{O}},[\% \mathrm{Al}]$ and $[\% \mathrm{O}]$ at point $\mathrm{E}$ of Fig. 7.

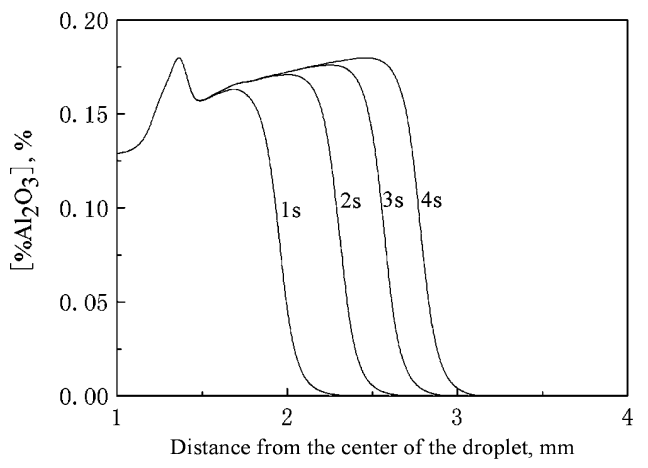

(a) the solid fraction increased from 0 to $0.9 .{ }^{11)}$ So the average oxygen content in the liquid phase is about 3 times of the average content in the total steel. In this case, the model is calculated with the initial oxygen content of $600 \mathrm{ppm}$, which is 3 times of the $200 \mathrm{ppm}$ oxygen content in steel. The calculating results are shown in Fig. 15.

From Fig. 15(a), in the area nearing the aluminium wire and the peak zone the curve is similar to the results of initial oxygen content equal to $200 \mathrm{ppm}$, but in the middle zone and outmost zone the curve become more flatness, as there is enough high content of oxygen in these two area the nucleation and the $S_{\mathrm{O}}$ values in all four zones are far above the critical value for nucleation of new inclusions, Fig. 15(b). So the growth of alumina inclusions is not as difficult as that results with the initial oxygen content of $200 \mathrm{ppm}$. And the peak value of $S_{\mathrm{O}}$ is decreased with the increase of distance from the aluminium wire, which leads to the decreasion of the number of inclusions with the farer distance from the aluminium. This trend is similar to that of initial oxygen content of $200 \mathrm{ppm}$, but more obvious.

\subsection{The Simulation of Solidification on the $\mathrm{MgO}$ Coating Copper Cooling Plate}

With the the $\mathrm{MgO}$ coating copper cooling plate, the time duration of solidificating process of steel droplet is increased to $9 \mathrm{~s}$, for the $\mathrm{MgO}$ plate decreasing the heat transfer flux. The simulation results of the droplet cooled on the $\mathrm{MgO}$ plate is shown in Fig. 16. Although the liquid phase lasts more time, the trend of the curve of the simulation results is similar to that case on the copper plate.

\section{Conclusion}

Alumina inclusion nucleated and growthed has been investigated during rapid solidification process of liquid steel droplet with certain initial oxygen content and aluminum in the center, using the mass transfer and reaction model. The findings are summarized as followings:

(1) The reaction zone between aluminum and oxygen in liquid steel is located in a limited zone at a certain fixed time and it is moved from center to outmost with the time going.

(2) High aluminium zone is gradually diffused from the center of the droplet to the outsider, while high oxygen zone in the droplet is withdrawed with even pace in the same direction in the same time.

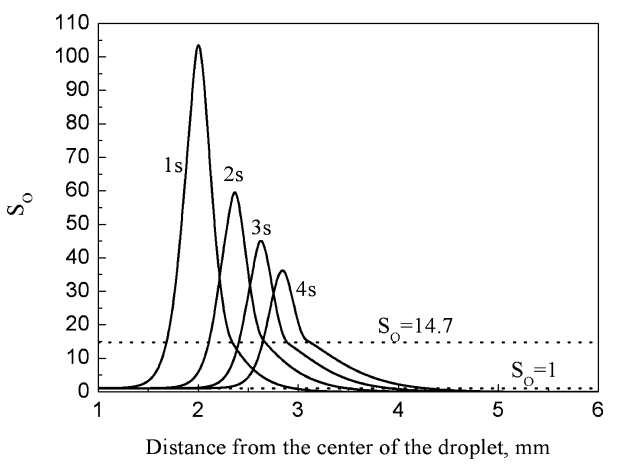

(b)

Fig. 15. Simulating the droplet with initial oxygen content of $600 \mathrm{ppm}$. 


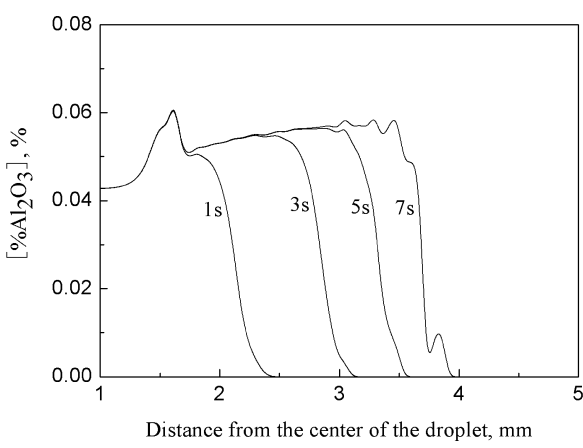

(a)

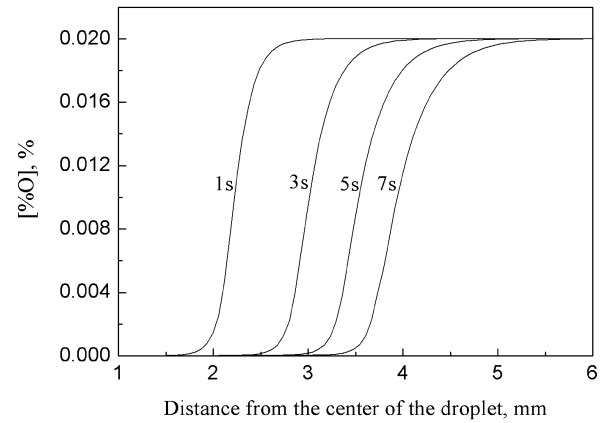

(c)

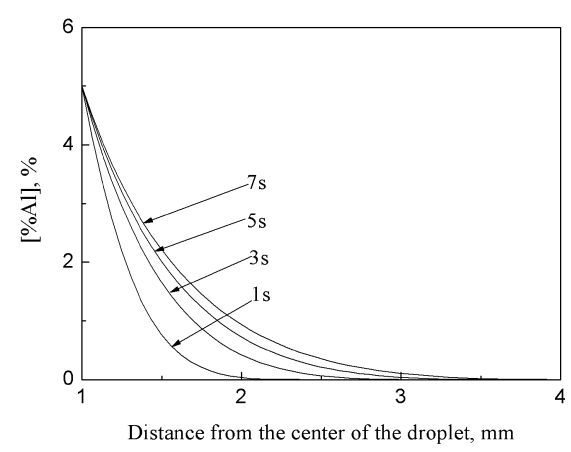

(b)

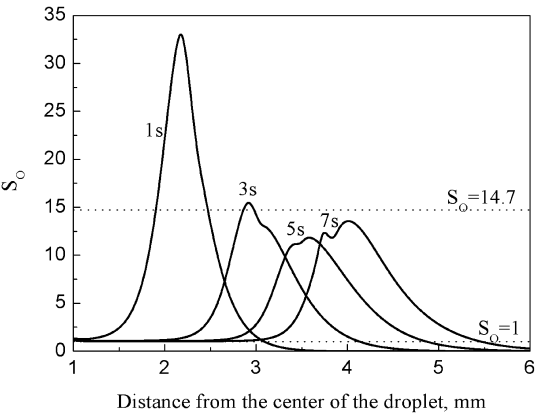

(d)

Fig. 16. Simulating the droplet cooled on the $\mathrm{MgO}$ plate with initial oxygen content of $200 \mathrm{ppm}$.

(3) Based on the distribution of $\mathrm{Al}_{2} \mathrm{O}_{3}$, the droplet can be divided to four regions: the zone nearing aluminum, the peak zone, the middle zone and the outmost zone.

(4) For the zone besides aluminum, the supersaturation degree $S_{\mathrm{O}}$ is very high at first, and then is decreased quickly, and the main part of oxygen in steel is absorbed by nucleation based on the computation of the model. The nucleation rate of inclusion in this zone is very high, the growth of inclusion is limited in a very short time.

(5) For the peak zone, there is a peak content of precipitated $\mathrm{Al}_{2} \mathrm{O}_{3}$. The observed straight-line bands of inclusions may be the sign of the thin located reaction zone, as the peak content of $\mathrm{Al}_{2} \mathrm{O}_{3}$ makes distribution of inclusion in this zone more visible.

(6) For the middle zone and the outmost zone, the main part of oxygen in steel is absorbed by growth of inclusion, the supersaturation degree $S_{\mathrm{O}}$ is not very high at first, the growth of inclusion is lasting for longer time. For outmost zone the aluminum content is low, so the reaction can not take place in each location.

\section{REFERENCES}

1) T. Gladman: The Physical Metallurgy of Microalloyed Steels, Maney, London, (1997), 39.

2) E. T. Turkdogan: J. Iron Steel Inst., 210 (1972), 21.

3) W.-C. Doo, M.-J. Jang, S.-C. Kang and K.-W. Yi: Proc. of 85th Steelmaking Conf., ISS, Warrendale, PA, (2002), 477.

4) L. Zhang and W. Pluschkell: Ironmaking Steelmaking, 30 (2003), 106.

5) T. Nakaoka, S. Taniguchi, K. Matsumoto and S. T. Johansen: ISIJ Int., 41 (2001), 1103.

6) J. Zhang and H.-G. Lee: Proc. of 2003 CSM Annual Meeting, The China Society for Metals (CSM), Beijing, (2003), 276.

7) K. Beskow, N. N. Viswanathan, L. Jonsson and Du Sichen: Metall. Mater. Trans. B, 32B (2001), 320.

8) F. Oeters: Mtallurgy of Steelmaking, Verlag Stahleison mbH, Duesseldorf, (1994), 156.

9) H. Suito and H. Ohta: ISIJ Int., 46 (2006), 33.

10) H. D. Brody and M. C. Fleming: Trans. Metall. Soc. AIME, 236 (1966), 615.

11) H. Q. Zhang, S. B. Zheng, Q. Zheng, Z. L. Liu and G. C. Jiang: Acta Metall. Sin. (China), 42 (2006), 745. 